\title{
Existimos e Resistimos: a prática da educação física nas comunidades Quilombolas
}

\author{
Exist and Resist: the practice of physical education in Quilombola communities \\ Existimos y Resistimos: la práctica de la educación física en las comunidades Quilombolas
}

Recebido: 05/11/2021 | Revisado: 12/11/2021 | Aceito: 18/11/2021 | Publicado: 28/11/2021

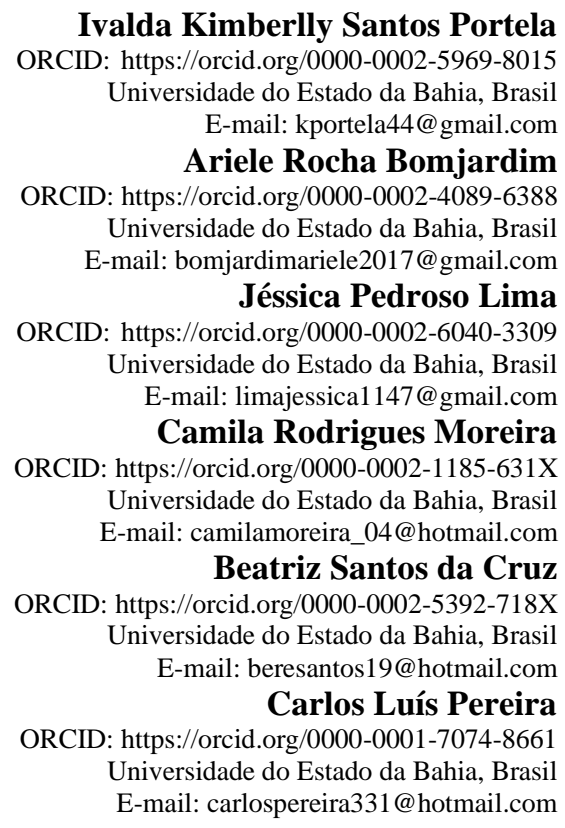

\begin{abstract}
Resumo
A proposta deste presente artigo é analisar o significado das concepções e suas formas de complexidade dos processos de ensino/aprendizagem, no campo da Educação Física escolar, em específico na educação quilombola. A educação quilombola acontece nas comunidades por meio do compartilhamento de conhecimentos e saberes entre todos. Objetivo do texto é apresentar informações acerca da Educação Física Escolar Quilombola os desafios de sua resistência e uma práxis pedagógica que tematizasse a cultura afro-brasileira. A metodologia adotada constitui-se de uma análise qualitativa de cunho bibliográfico e interpretativa, tendo como principal teórico de base Zabala, dentre outros. Em virtude do que foi mencionado concluímos que nesse artigo foi demostrado que a educação quilombola vem sendo incluída cada vez mais com o intuito de transmitir os conhecimentos e tradições de sua cultura, assim se tornando de extrema importância, tendo como meio a Educação Física uma forma incluir esses novos conhecimentos nas salas de aula. Na perspectiva de Zabala a avaliação ela vai poder ser dividida e aplicadas em quatro diferentes conteúdos sendo os mesmo os factuais, conceituais, procedimentais e os atitudinais trazendo assim cada um com sua concepção de avaliação, frisando assim a importância a educação na vida do aluno, sendo assim a escola um espaço de novos conhecimentos e vivencias.
\end{abstract}

Palavras-chave: Educação quilombola; Educação física; Ensino; Avaliação.

\begin{abstract}
The purpose of this article is to analyze the meaning of conceptions and their forms of complexity in teaching/learning processes in the field of school Physical Education, specifically in quilombola education. Quilombola education takes place in communities through the sharing of knowledge and knowledge among everyone. The aim of the text is to present information about Quilombola School Physical Education, the challenges of its resistance and a pedagogical praxis that thematizes Afro-Brazilian culture. The adopted methodology consists of a qualitative analysis of bibliographic and interpretive nature, having as the main theoretical base Zabala, among others. In view of what was mentioned, we conclude that this article demonstrated that Quilombola education has been increasingly included with the aim of transmitting the knowledge and traditions of their culture, thus becoming extremely important, having Physical Education as a means. include this new knowledge in the classroom. In Zabala's perspective, the assessment will be able to be divided and applied in four different contents, the same being the factual, conceptual, procedural and attitudinal, thus bringing each one with its own assessment concept, thus emphasizing the importance of education in the student's life, thus, the school is a space for new knowledge and experiences.
\end{abstract}

Keywords: Quilombola education; Physical education; Teaching; Evaluation. 


\section{Resumen}

El propósito de este artículo es analizar el significado de las concepciones y sus formas de complejidad en los procesos de enseñanza / aprendizaje en el campo de la Educación Física escolar, específicamente en la educación quilombola. La educación quilombola se lleva a cabo en las comunidades a través del intercambio de conocimientos y conocimientos entre todos. El objetivo del texto es presentar información sobre la Educación Física Escolar Quilombola, los desafíos de su resistencia y una praxis pedagógica que tematice la cultura afrobrasileña. La metodología adoptada consiste en un análisis cualitativo de carácter bibliográfico e interpretativo, teniendo como base teórica principal a Zabala, entre otros. A la vista de lo mencionado, concluimos que este artículo demostró que la educación quilombola se ha incluido cada vez más con el objetivo de transmitir los conocimientos y tradiciones de su cultura, adquiriendo así una enorme importancia, teniendo como medio a la Educación Física. el salón de clases. En la perspectiva de Zabala, la evaluación podrá ser dividida y aplicada en cuatro contenidos diferentes, siendo los mismos el factual, conceptual, procedimental y actitudinal, trayendo así cada uno con su propio concepto evaluativo, enfatizando así la importancia de la educación en el la vida, por tanto, la escuela es un espacio de nuevos conocimientos y experiências.
\end{abstract}

Palabras clave: Educación quilombola; Educación física; Aprendiend; Evaluació.

\title{
1. Introdução
}

Atualmente quando se fala de educação e avaliação logo se pensa nos resultados obtidos pelos alunos, isso numa forma exclusiva continua sendo o principal alvo de qualquer aproximação ao fato avaliador. A aprendizagem consiste na retenção de informações e demonstrações transmitidas, que serão gravadas nas mentes individuais mediante a repetição sistemática de exercícios, visando à formação de hábitos aplicáveis às situações semelhantes. A aprendizagem é receptiva e mecânica, recorrendo-se, frequentemente, à coação.

A educação, como dever do Estado e realidade social não foge ao controle do Direito. A Educação é um instrumento imprescindível para que o indivíduo possa reconhecer a si próprio como agente ativo na modificação da mentalidade de seu grupo e ser promotor dos ideais humanos [...] (Nunes \& Souza, 2013). A educação ganhou lugar de destaque na Constituição Federal de 1988 de modo a expandir o conhecimento da sociedade brasileira, tendo o Estado a obrigação de oferecer um sistema educacional de qualidade a todos os brasileiros. Para tanto, a Constituição Federal de 19889, em seu artigo 205, enunciou o direito à educação como um direito social de todos e dever do Estado e da família.

Enfocando a avaliação na área escolar, Sousa $(1995,1997)$ afirma que a avaliação do rendimento permite verificar se os objetivos de determinado curso foram atingidos, considerando que é o planejamento e o ensino que vai determinar o caminho a ser seguido. Para Almeida (1992) há duas funções estabelecidas para a avaliação do rendimento escolar. A primeira, diz respeito às funções gerais que visam o planejamento, a tomada de decisão, a seleção, a classificação e o ajuste das práticas pedagógicas. A segunda, engloba funções específicas que buscam, por meio do diagnóstico, um avanço no processo pedagógico com o intuito de adequar e agrupar os alunos em função dos resultados obtidos.

Esta se concretiza, por meio de diversas variáveis que se inter-relacionam de forma complexa, e se expressa no microssistema da sala de aula.

Nessa perspectiva Zabala (1998) revela que é frequente encontrar argumentos dos professores sobre a impossibilidade de realizar mudanças em algumas metodologias, seja na distribuição do tempo, nos agrupamentos, ou na avaliação. Esses argumentos vão de encontro aos referentes teóricos que aconselhariam essas mudanças.

Ainda segundo Zabala (1998) "Por trás de qualquer proposta metodológica se esconde uma concepção do valor que se atribui ao ensino, assim como certas ideias mais ou menos formalizadas e explícitas em relação aos processos de ensinar e aprender."

Weisz (2002) concorda quando afirma que "a aprendizagem é vista como produto da ação e reflexão do aprendiz". Segundo a autora "o sujeito é compreendido como alguém que sabe algumas coisas e que ao se deparar com questões que a ele se colocam como problemas, depara-se também com a necessidade de superação e o conhecimento novo aparece como resultado 
de um processo de ampliação, diversificação e aprofundamento do conhecimento anterior que ele já tem”. (Weisz, 2002.) O professor que pretende qualificar-se melhor para lidar com a aprendizagem dos alunos precisa estudar e desenvolver uma postura investigativa (Weisz, 2002 p. 45). Além disso, “[...] deve formar o cidadão daquele momento histórico, naquele país, naquela circunstância. A sociedade é que decide o que suas crianças e jovens devem aprender.” (Weisz, 2002.)

Este estudo motiva-nos, a busca da compreensão do processo de ensino/aprendizagem que se desenvolve quando se lança mão do Estudo do Meio como procedimento de ensino, conforme nos ensina Zabala (2007) que a aprendizagem depende das características singulares de cada um dos aprendizes e corresponde, em grande parte, às experiências que cada um viveu desde o nascimento.

Ainda hoje, quando se pensa em quilombo, a primeira ideia que vem à mente é a de que foi um local isolado, no meio da mata, formado por escravos negros fugidos. Consagrada pela História dominante no Brasil, essa visão ainda permanece arraigada no senso comum remetendo-nos a um passado remoto de nossa história que data de dois de julho de mil setecentos e quarenta. Nessa data, o Conselho Ultramarino, órgão responsável pelo controle central da colônia, definiu o quilombo como "toda habitação de negros fugidos que passem de cinco, em parte despovoada, ainda que não tenha ranchos levantados nem se achem pilões neles" (Moura,1988).

A educação quilombola acontece nas comunidades por meio do compartilhamento de conhecimentos e saberes entre todos. Logo, a educação quilombola na escola deve partir dos princípios de uma educação integral, isto é, reconhecer o território e a comunidade como parte do processo educativo. Veremos que a importância da educação quilombola é um modelo bem diferenciado de educação escolar que se centraliza na realidade das comunidades quilombolas, valorizando a territorialidade como espaço educativo, e estabelece contatos respeitosos com valores culturais e ancestrais cultuados pela comunidade.

Sendo assim a proposta da educação nacional acentua-se com o reconhecimento à diversidade de identidades na valorização do ser humano, e considera no processo, o direito de ser aceito nas especificidades que compõem a nação brasileira. Nesse sentido, percebe-se que a diferença precisa ser levada em consideração em todos os contextos, sendo a escola um dos espaços importantes para colaborar na superação de todas as formas de discriminação e racismo.

Sendo assim, as propostas pedagógicas, assim como os regimentos escolares, devem acolher com autonomia e senso de justiça o princípio da identidade pessoal e coletiva dos professores, dos alunos e de todos que convivem nesse espaço social.

Nesse cenário de luta para garantir os direitos civis do povo quilombola desencadeou-se também as reivindicações pela educação escolar quilombola enquanto Políticas Educativas e política educacional. Problemática denunciada constantemente pelo movimento negro, pela Coordenação Nacional de Articulação das Comunidades Negras Rurais Quilombolas (CONAQ) e setores da sociedade que exigem a educação pública e de qualidade para todos (Brasil, 2011).

Entretanto essa compreensão da ação escolar também deve se refletir nas Comunidades Quilombolas, nas quais as instituições de ensino estão inseridas, por meio de seu calendário escolar contemplando atividades curriculares e extracurriculares. Pode, também, promover ampla reflexão sobre a consciência democrática nacional, uma vez que as múltiplas formas de diálogo contribuem para a construção de identidade afirmativa capaz de protagonizar ações solidárias e autônomas de constituição de conhecimento e valores fundamentais para a vida cidadã. Dessa forma, o processo educacional é concebido como indissociável da relação entre conhecimentos, linguagens e afetos constituintes dos atos de ensinar e aprender.

\section{A gênese da educação}

A prática educativa implica entender que tipo de atividade é a educação. No mundo ocidental, a referência é a Grécia Clássica. Desde a sua origem, a educação foi uma tarefa coletiva. Inicialmente, quando ainda não existiam escolas como as de hoje, a educação era ministrada pela própria família, em consonância com a tradição religiosa. Com o advento da polis surgiram as primeiras escolas. 
A educação é pensada desde a Antiguidade, a prática de educar constitui o princípio pelo qual os grupos humanos conservam e asseguram suas peculiaridades físicas e espirituais. Se desde a sua gênese a educação era uma tarefa compartilhada coletivamente, nas sociedades primitivas cabia aos adultos apresentar às crianças e aos jovens as normas e os valores do grupo.

Não é possível falar de um começo da educação, pois na verdade ela principia com a própria humanidade e se atualiza para cada contexto social, histórico, político e cultural em um determinado tempo e lugar. Toda sociedade educa, haja vista transmitir às gerações costumes, hábitos, maneiras de fazer e de conhecer. Por outro lado, o ensino não nasceu colado à humanidade, começou com os gregos, quando questionaram a natureza, a sociedade, os hábitos, a maneira de governar e de educar. Foi nesse contexto que sofistas, Sócrates e Platão, propuseram uma maneira de educar. Os sofistas são considerados os primeiros professores.

Em decorrência, dado o grau de desenvolvimento da sociedade, que naturalmente é compelida a necessitar de educação, emerge a escola como atividade setorizada, conferida a especialistas. O ato de educar, que antes era difuso e exercido por todos, torna-se privilégio de algumas pessoas, que são os professores, e, de modo geral, realizado em lugares específicos, as escolas.

O termo educação, comumente referido ao ato educativo, designa a prática educativa social, situada num determina do tempo e espaço. A educação é decorrente das relações entre os seres humanos, e, uma vez que o desenvolvimento social é tributário da consciência das produções que orientam a vida humana, a história da prática educativa está condicionada pela transformação dessas relações e produções consideradas adequadas a cada sociedade.

A educação existe em diferentes espaços e tempos, nas mais variadas formas, faz parte do conjunto de necessidades humanas e é condição precípua do processo de humanização. O desenvolvimento da sociedade, entre outros aspectos, trouxe a exigência de mais educação, por conseguinte, influencia na maneira que cada grupo social constrói sua prática educativa. O sentido e o significado da prática educativa não permanecem indiferentes a essas crises sociais, culturais e ideológicas. Se a compreensão do processo de ensino passa pela consideração do conjunto das atividades educativas exigidas pela sociedade, logo não se pode pensar a prática educativa restrita ao espaço da sala de aula.

A educação não é propriedade de um indivíduo, "mas pertence por essência à comunidade". Essa, pois, tem grande influência no esforço de educar seus membros de acordo com o sentir de cada nova geração. A prática educativa é ação social intencional, é parte integrante da vida, do crescimento da sociedade. Todos nós desenvolvemos prática educativa, independentemente do contexto, da concepção filosófica e pedagógica. (Jaeger, 2010).

Em Freire (2011), a natureza humana não é portadora de uma especificidade da qual se extrai sua essência, como entendia a pedagogia da essência. Nesses termos, embora aconteçam circunstâncias de opressão, ainda existe a possibilidade de que o indivíduo se transforme.

O problema de quem ensina e aprende não está limitado ao ato de comunicar conhecimento e o processo pelo qual se chegou a ele, mas, notadamente, ao problema de permitir vivência produtiva de conhecimento

A práxis é uma totalidade prático-social que pode adquirir diferentes formas e níveis se levar se em conta a matéria sobre a qual é exercida a prática transformadora. (Freire, 2005).

\section{Comunidades Quilombolas e Pertencimento}

A fim de recuperar a ancestralidade que, por vezes, a escola distorce e resume à escravidão, as comunidades quilombolas começaram, por volta de 1980, a se organizar em prol de uma educação quilombola.

Desde então, foram instituídas legislações para respaldar a garantia da educação dos quilombolas, como a Lei $\mathrm{N}^{\circ}$. 10639 (2003), que tornou obrigatório o ensino sobre História e Cultura Afro-Brasileira nas escolas, as Diretrizes Curriculares Nacionais para a Educação das Relações Étnico-raciais (2007) e as Diretrizes Curriculares Nacionais para a Educação Escolar Quilombola (2012). 
Hoje, existem pouco mais de 2300 escolas localizadas em áreas remanescentes de quilombos no País para cerca de 5 mil comunidades quilombolas, segundo dados de 2017 do Governo Federal. Destas, somente 34\% utilizam materiais didáticos específicos para atendimento à diversidade sociocultural quilombola.

O território tem sua fala expressa por meio do recontar o passado e atualizar tradições vinculadas à vida nos lugares para as crianças e jovens, à organização social que luta pela garantia da permanência nas terras.

Conforme Moura (1981), onde houve escravidão existiu resistência, caracterizando o quilombo como um dos movimentos mais fortes de reação à escravidão. Além de não haver políticas reparatórias ou indenizatórias pelos três séculos de exploração escravista, por meio da construção ideológica do branqueamento vivenciou-se um imaginário de harmonia e democracia racial que buscou apagar da memória social as lutas e as dores da escravidão. Após a abolição iniciou-se uma trajetória de exclusão social e invisibilidade, que na prática negou direitos aos afrodescendentes e desconheceu os territórios quilombolas na estrutura agrária brasileira.

De acordo com Almeida (2002), é necessário superar a concepção de que os quilombos eram grupos estáticos, sem resistência e negadores do sentido de mobilidade, inter-relações e diversidade no seu interior. O quilombo tornou-se emblemático no processo de resistência ao regime escravista, que se sustentava na força física e no poder simbólico.

A territorialidade passa a ser o ponto de partida da realidade social para a construção de um processo pedagógico significativo, pois a memória, por meio das narrativas vinculadas ao território vivido, permite a análise da história mais ampla em que se inserem as comunidades, na formação social e territorial brasileira.

No nosso contemporâneo, pensar em igualdade social no Brasil por vezes torna-se um movimento utópico, quer seja pela dinâmica da realidade sociopolítica, que cada vez mais acentua a estratificação social ou pela luta por uma sociedade justa que a cada dia dá sinais de sua individualização. Portanto, tecer uma análise sobre as relações étnico-raciais no campo da Educação Física é uma escolha política, no sentido de ir contra todo o movimento social de exclusão.

O currículo há muito tempo deixou de ser apenas uma área meramente técnica, voltada para questões relativas a procedimentos, técnicas e métodos. Já se pode falar agora em uma tradição crítica do currículo, guiada por questões sociológicas, políticas, epistemológicas (Moreira \& Silva, 1994). Nessa perspectiva, o currículo é considerado um artefato social e cultural, a Educação Escolar Quilombola deve ser projetada de forma que além de manter as disciplinas pedagógicas, possibilitem a eles transmitir suas culturas aos seus descendentes.

A formulação de uma proposta pedagógica para a educação quilombola certamente carece de pesquisas que envolvam aqueles saberes comunitários e um intercâmbio de conhecimentos entre diversas áreas. A interdisciplinaridade torna-se necessária para a abertura de diálogos entre sociologia, história, geografia, antropologia, educação física e outras ciências que venham a contribuir com a elaboração de um currículo pertinente a essa realidade.

Apesar dos avanços estabelecidos nos últimos anos por meio de vários segmentos sociais, ainda há um longo caminho a ser percorrido para a construção de uma sociedade plural. Neste contexto, a escola deveria ser um espaço de aprendizado, combatendo qualquer forma de discriminação e preconceito, promovendo o respeito às diferenças, a valorização do humano e da identidade cultural de todos os povos.

\section{Educação Física Escolar}

Quando falamos em direitos no campo educacional, referimo-nos também ao currículo escolar que será abordado nessas comunidades tradicionais, pois é necessário discutir e buscar por meios de ações concretas que sejam eficazes para atender ao conjunto de especificidades desses povos.

A cultura dos povos tradicionais, seja afro-brasileira ou indígena, já possui a tradição de transmitir os conhecimentos e tradições dos mais velhos aos mais novos. Um hábito utilizado entre eles para manter a identidade do seu povo. 
Dentre as várias conquistas dos movimentos sociais pelos povos africanos e indígenas, alcançadas com muita luta e resistência, faremos referência a Lei 10639/2003 e a Lei 11.645/2008, que representaram passos importantes para a visibilidade da cultura afro-brasileira e indígena dentro da escola, caracterizando a afirmação das identidades étnicas, a recuperação das memórias históricas e valorização das línguas e conhecimentos desses povos.

A disciplina de Educação Física para cumprir a Lei No 10.369/2003 e a Lei 11. 645/2008, que tratam sobre a inclusão da História e Cultura dos povos afro-brasileiros e indígenas, respectivamente, deve executá-la de forma a agregar os conhecimentos necessários das diversas culturas pré-existentes, tendo as práticas corporais como elemento a ser desenvolvido durante a aula. Dessa forma, deverá contribuir para o desenvolvimento de um currículo escolar que preserve e valorize a originalidade dessas culturas.

É preciso avançar na discussão sobre as Leis No 10.639/03 e 11.645/08, dimensionando a tensão entre sua aplicabilidade e suas propostas, pois entendemos que "desconstruir" conceitos, reparar culturas e combater preconceitos demandam uma luta interdisciplinar. Tal decisão se edificará também por meio de um processo amplo de negociação política, envolvendo a escola, a comunidade e a sociedade. Diante desta compreensão, atentamos para alguns desafios propostos pelas Leis 10.639/03 e 11.645/08, especialmente no ensino da Educação Física e na formação de professores da área.

As Novas Diretrizes Curriculares da Educação Básica, são resultados amplos de sistemas educativos em seus vários níveis (municipal, estadual e federal) para que as crianças, adolescentes, jovens e adultos que ainda não tiveram a oportunidade, possam se desenvolver plenamente, recebendo uma formação de qualidade correspondente à sua idade e nível de aprendizagem, respeitando suas diferentes condições sociais, culturais, emocionais, físicas e étnicas.

Nesse sentido, as Diretrizes Curriculares Nacionais Gerais para a Educação Básica visam estabelecer bases comuns nacionais para a Educação Infantil, o Ensino Fundamental e o Ensino Médio, exemplo disso são as modalidades com que eles podem se apresentar, a partir das quais os sistemas federal, estaduais, distrital e municipais, por suas competências próprias e complementares, as suas orientações assegurando a integração curricular das três etapas sequentes desse nível da escolarização, essencialmente para compor a sociedade. Além das avaliações que já ocorriam de forma sistematizada, marcou o início da elaboração deste Parecer, particularmente, a Indicação CNE/CEB nº 3/2005, assinada pelo então conselheiro da CEB, Francisco Aparecido Cordão, na qual constava a proposta de revisão das Diretrizes Curriculares Nacionais para a Educação Infantil e para o Ensino Fundamental.

Sendo assim, justificamos que tais diretrizes encontram se em total poder normativo segundo avaliação nacional sobre a matéria nos últimos anos, e superadas em decorrência dos últimos atos legais que particularmente ao tratar da matrícula no Ensino Fundamental de crianças de 6 (seis) anos e consequente ampliação do Ensino Fundamental para 9 (nove) anos de duração. Imprescindível acrescentar que a nova redação do inciso I do artigo 208 da nossa Carta Magna, dada pela Emenda Constitucional $n^{\circ}$ 59/2009, assegura Educação Básica obrigatória e gratuita dos 4 aos 17 anos de idade, inclusive a sua oferta gratuita para todos os que a ela não tiveram acesso na idade própria.

É Dado seu teor expressivo, as práticas corporais materializam formas de interação dos diversos grupos que compartilham a paisagem social, intimamente relacionada ao contexto histórico em que foram ou são criadas e recriadas. Nessa perspectiva curricular, denominada "cultural", a experiência escolar é um campo aberto ao debate, ao encontro de culturas e à confluência de práticas corporais pertencentes aos vários setores sociais.

O currículo cultural da Educação Física é uma arena de disseminação de sentidos, de polissemia, de produção de identidades voltadas para a análise, a interpretação, o questionamento e o diálogo entre e as culturas e a partir delas (Neira, 2011). 


\section{Avaliações de conteúdos e didática na Educação Física Escolar}

Considerando o exposto, o trabalho de Franco (2012) discute as práticas pedagógicas a partir da relação com o objeto da Didática. Segundo a autora, prática pedagógica diz respeito às práticas sociais com propósito intencional de realiza-se no pedagógico, e prática docente torna-se pedagógica quando, além de ser prevista a intencionalidade, ocorre que a consciência se mantém ativada tanto no planejado quanto no realizado.

A finalidade da escola é promover a formação integral dos alunos, segundo Zabala, que critica as ênfases atribuídas ao aspecto cognitivo. Para ele, é na instituição escolar, através das relações construídas a partir das experiências vividas, que se estabelecem os vínculos e as condições que definem as concepções pessoais sobre si e os demais.

A partir dessa posição ideológica acerca da finalidade da educação escolarizada, é conclamada a necessidade de uma reflexão profunda e permanente da condição de cidadania dos alunos e da sociedade em que vivem. Sobre os conteúdos da aprendizagem, seus significados são ampliados para além da questão do que ensinar, encontrando sentido na indagação sobre por que ensinar.

Desse modo, acabam por envolver os objetivos educacionais, definindo suas ações no âmbito concreto do ambiente de aula. Esses conteúdos assumem o papel de envolver todas as dimensões da pessoa, caracterizando as seguintes tipologias de aprendizagem: factual e conceitual (o que se deve aprender?), procedimental (o que se deve fazer?), e atitudinal (como se deve ser?).

Para a educação física escolar, essa caracterização dos conteúdos parece apontar avanços, na medida em que chama atenção para a dimensão conceitual, bem como operacionaliza o antigo conceito denominado afetivo (atitudinal), tradicionalmente desenvolvido em nossa área de maneira espontaneísta. Sobre a concepção de aprendizagem, o autor afirma que não é possível ensinarmos sem nos determos nas referências de como os alunos aprendem, chamando a atenção para as particularidades dos processos de aprendizagem de cada aluno (diversidade).

O construtivismo é eleito como concepção metodológica em virtude da validação empírica de uma série de princípios psicopedagógicos: os esquemas de conhecimento, o nível de desenvolvimento e dos conhecimentos prévios e a aprendizagem significativa. Baseada nessa concepção, a aprendizagem dos conteúdos apresenta características específicas para cada tipologia.

Os PCNs, nos seus documentos do ensino fundamental11, dão papel de destaque para os temas transversais. Daí a importância da compreensão do significado da transversalidade. Em contrapartida, as DCNs do ensino médio referenciam como princípio básico para este nível a interdisciplinaridade. Portanto, o conhecimento sobre as novas formas de organização é necessário para a compreensão e reflexão destes documentos e para o encaminhamento de novas propostas de ensino. (BRASIL, 1998)

No ensino da educação física, constata-se o predomínio das dimensões atitudinais e procedimentais dos conteúdos, não enfatizando a dimensão conceitual e os respectivos materiais curriculares (quadro negro, audiovisuais, livros didático e paradidático).

Para esse fim, propõe-se pensar a educação quilombola com base nos contextos de uso do território, da etnicidade e da memória presentes nas narrativas dos sujeitos no intuito de construir metodologias que proporcionem aprendizagens tendo como ponto de partida elementos referentes às realidades locais das comunidades

Por fim, o objetivo do texto é apresentar informações acerca da Educação Física Escolar Quilombola os desafios de sua resistência e uma práxis pedagógica que tematizasse a cultura afro-brasileira no contexto da singularidade territorial e suas formas de ensino/aprendizagem, os desafios de suas práticas pedagógica referentes ao contexto de singularidade brasileira e suas interfaces com a educação física escolar.

Para tanto, dividimos o texto nas seguintes seções: introdução, metodologia, resultados e discussões, e considerações finais. 


\section{Metodologia}

A metodologia adotada constitui-se de uma análise qualitativa de cunho bibliográfico e interpretativa, que conforme Gil (2011) esse tipo de pesquisa propõe a descoberta, a interpretação contextualizada e o relato de modo aprofundado dos fatos sociais do cotidiano. Para realização dessa pesquisa percorremos as leituras de Zabala (1998), Almeida (2002), Moreira (1981), Neira (2011) dentre outros.

A pesquisa trilhou caminhos através de consulta em livros, periódicos, teses e dissertações sobre o assunto, tendo como fundamental recorte teórico os métodos de avaliação dos conteúdos na perspectiva do teórico Zabala e sua aplicação na Educação Quilombola no campo da Educação Física Escolar.

Após a coleta dos dados bibliográficos apresentamos na seção resultados e discussões a argumentação acerca dos métodos de avaliação. Depois dessa apresentação, expomos acerca da importância da Educação Quilombola e resistência dos povos afrodescendentes. Por fim, as considerações finais concluindo o texto.

\section{Resultados e Discussão}

A educação nacional frisa acentuar com o reconhecimento à diversidade de identidades na valorização do ser humano. Desta forma, a Educação é um ato de cultura, e segundo Santos (2011,), "A escola tornou-se uma convenção de caráter social. Ela é um lócus da cultura escrita, científica e epistemológica, por isso configura-se como a cultura escolar”. Sendo, desse modo, um fenômeno que resulta na formação do sujeito, visto que educar é a arte de ensinar, viver e conviver, no qual faz a significação do indivíduo, que se materializa na sociedade e o espaço escolar demonstra esse sentido de construção e reprodução social e cultural

A escola também é um dos espaços mais importante para superar questões de discriminação racial, desta forma as propostas pedagógicas, devem acolher com autonomia e senso de justiça o princípio da identidade pessoal e coletiva de todos.

Segundo Zabala (1998), a melhora da prática educativa, passa pelo conhecimento e pelo controle das variáveis que intervém nela, isso torna necessário que o professor disponha de referenciais que ajudem a interpretar os obstáculos vivenciados na sala de aula. Nesse caso o professor deve buscar novos conhecimentos para inovar sua prática educativa e adequar as exigências da sociedade.

O ensino atende à diversidade dos alunos, portanto a forma de ensino não pode se limitar a um único modelo. Conforme Zabala (2015) "é preciso introduzir, em cada momento, as ações que se adaptem às novas necessidades informativas que surgem constantemente".

Ainda para Zabala, o processo de ensino não pode se limitar a um único modelo e sim há diferentes modelos, pois é necessário atenção à diversidade de alunos em sala de aula.

A educação Quilombola requer pedagogia própria, respeito à especificidade étnico-racial e cultural de cada comunidade, materiais didáticos e paradidáticos específicos que atentem para os princípios constitucionais, a Base Nacional Comum e aos princípios que orientam a educação básica brasileira. Além disso, esses materiais devem ser oferecidos nas escolas quilombolas e naquelas escolas que recebem alunos quilombolas fora de suas comunidades de origem. Segundo Silva e Melo, [...] a Lei de Diretrizes e Bases da Educação (LDB) e os Parâmetros Curriculares Nacionais (PCN) são documentos oficiais que orientam o sistema educacional no país. É a partir deles que são elaborados os planejamentos de ensino nas escolas e os critérios de avaliação de livros didáticos pelo Programa Nacional de Livros Didáticos (PNLD). E é com base nesses documentos, ainda, que os livros didáticos aprovados pelo PNLD são orientados (Silva \& Melo, 2013).

O Currículo, e o material didático/pedagógico, deve seguir os eixos orientadores gerais da educação brasileira e se referenciar nos valores das comunidades quilombolas, como a cultura, as tradições, o mundo do trabalho, a terra, a 
territorialidade, a oralidade e a memória. Deverão se fazer presentes nos currículos a ancestralidade, o trabalho, a estética, as lutas pela terra e pelo território e o desenvolvimento sustentável dessas comunidades (Brasil, 2010).

Para Sacristán (2000), "O currículo se expressa em usos práticos, que, além disso, tem outros determinantes e uma história”. Segundo Sacristán para que o currículo se efetive como prática é necessário entender o contexto social e cultural das comunidades quilombolas, é preciso desenvolver uma educação que traga envolvimento com a história desses sujeitos sociais para que eles se reconheçam e queiram ser cada vez mais reconhecidos na sociedade em geral.

Entretanto, a Educação Escolar Quilombola não apresenta nenhuma perspectiva para os quilombolas, exceto incentiválos a ler e a escrever. Percebe-se que há um baixo índice de materiais didáticos produzidos pelos sistemas estaduais de ensino, tais materiais têm pouca visibilidade, e pouca participação das comunidades quilombolas na elaboração, são também, deficientes na demonstração das variedades e diversidades étnicas dos quilombos existentes no nosso país. Essa modalidade de ensino necessita de pesquisas que envolvem saberes comunitários, que efetivem a abertura de diálogos que contribuem com a elaboração de um currículo pertinente a essa realidade. Embora tenha ocorrido avanços nos últimos anos através de segmentos sociais, a construção de uma sociedade plural ainda está longe da nossa realidade atual.

Segundo Giroux (1997) o sistema escolar falho em reconhecer a relação entre a escolarização e a sociedade mais ampla; para o autor não seria suficiente apenas uma mudança no currículo, sendo necessário mudanças em vários fatores, tais como a preparação inadequada dos professores, materiais descontextualizados aos alunos e a própria cultura escolar. Fica evidente a importância de fazer um trabalho contínuo de resgate, construção e fortalecimento da identidade quilombola dentro e fora das escolas, reforçando e contribuindo na luta pelos direitos das comunidades.

\section{Conclusão}

A perspectiva de Zabala a avaliação ela vai poder ser dividida e aplicadas em quatro diferentes conteúdos sendo os mesmo os factuais, conceituais, procedimentais e os atitudinais trazendo assim cada um com sua concepção de avaliação, frisando assim a importância a educação na vida do aluno, sendo assim a escola um espaço de novos conhecimentos e vivencias

Em virtude do que foi mencionado concluímos que nesse artigo foi demostrado que a educação quilombola vem sendo incluída cada vez mais com o intuito de transmitir os conhecimentos e tradições de sua cultura, assim se tornando de extrema importância, tendo como meio a Educação Física uma forma incluir esses novos conhecimentos nas salas de aula, assim ampliando cada vez mais o currículo, assim não deixando de lado seus costumes, sobretudo podemos propor que com base nesse estudo que a educação quilombola deve haver mais visibilidade e participação, pois sendo assim a escola um dos espaço mais importantes para a visibilidade a essa cultura.

De acordo com a Resolução CNE/CEB N 3, de 10 novembro de 1999 as escolar indígenas passariam a ser reconhecidas como aquelas localizadas em terras de habitadas por comunidades indígenas, já a Resolução CNE/CEB N8, de 20 de novembro de 2012, vem abordando que as escolas quilombolas são aquelas localizadas em quilombos, contudo a lei de diretrizes e Bases da Educação Nacional ( LDB - 9.394/1996) no artigo 32 vem frisando que as comunidades indígenas deve utilizar de suas línguas maternas e já no artigo número 78 vem abordando que a educação escolar dos povos indígenas deve ser bilíngue, visando assim a suas identidades étnicas, abordando assim um cunho amplo conhecimento novas experiências, sendo assim Brasil cheio de novas culturas e etnias não sendo muito estudado por falta de um currículo mais amplo.

Contudo, concluímos através deste estudo frisar que a educação quilombola deve ser incluída e executada de forma correta assim não deixando de lado seus costumes, suas tradições, assim abrangendo novos conhecimentos abordando de forma significava cada pessoa sendo assim a escola um espaço novo experiências. 


\section{Referências}

Almeida, A. M. F. P. M. (1992); Um estudo sobre a avaliação da aprendizagem em um curso superior de ciências agronômicas Tese de Doutorado. Faculdade de Educação da Universidade Estadual de Campinas, Campinas.

Brasil. Lei no. 9.394/96 (1998) - Diretrizes e Bases da Educação Nacional; PCN, Parâmetros Curriculares Nacionais. Secretária de Educação Fundamental. Brasília; MEC/SEF.

Brasil, (2011) Boletim "Territórios Negros", ano 8, n 33. 1 (1988). Ato das disposições constitucionais transitórias.

Brasil. (2003). Casa Civil. Lei 10.639, de 09 de janeiro de 2003. Diário Oficial [da] República Federativa do Brasil. Poder Executivo, Brasília, DF, 10 jan. 2003.

Silva G. \& Raquel, M.; Karoline, R. A lei 11.645/08 e a sua abordagem nos livros didáticos do ensino fundamental. Intertextos. v. 13 , n. 2.

Educação como prática de liberdade (2011). (14 ed). Paz e Terra.

Editora Brasiliense (1981). Os quilombos e a Rebelião Negra.

Franco, M. A. S. (2012) Práticas pedagógicas nas múltiplas redes educativas. In: LIB NEO, Carlos; ALVES, Nilda. Temas de Pedagogia diálogos entre didática e currículo.: Cortez, 2012. p. 169-188

Freire, P. (2015) Pedagogia do oprimido. (49. ed.): Paz e Terra.

Gil, A. C. (2011) Metodologia do ensino superior (4. ed) Atlas.

Giroux, H. A (1997) Os professores como intelectuais. Rumo a uma pedagogia crítica da aprendizagem.: Artmed.

Brasil. Lei 11.645, de 10 de março de (2008). Disponível em: Acesso em: 2013-06-0

Ministério da Educação (MEC). (2010) Educação escolar quilombola. Diário Oficial da União, Brasília, DF, 09 jul.

Jaeger, W. (2010). Paideia formação do homem grego. (5 ed): Martins Fontes.

Moreira, A. F., Silva T. T. (1998) Currículo, cultura e Sociedade. Cortez Rebeliões da senzala - quilombos, insurreição, guerrilhas.: Mercado Aberto.

Moura. C (1998). Rebeliões da senzala - quilombos, insurreição, guerrilhas. Porto Alegre: Mercado Aberto.

Neira M. G (2011) O currículo cultural da educação física em ação: uma perspectiva dos seus autores. Tese de Doutorado. Universidade de São Paulo.

Nunes, M. L. R. L. \& Souza, J. P. (2013). Cadernos de educação em direitos humanos: educação e direitos humanos: diretrizes nacionais. Brasília, DF: Secretaria de Direitos Humanos.

Resolução CNE/CEB No 03 (1999) Fixa Diretrizes Nacionais para o funcionamento das escolas indígenas e dá outras providências.

Sacristán, J, (2000) Gimeno. O currículo: uma reflexão sobre a prática. (3.ed.): Artmed.

Santos. at all A. C. B. A, (2011). Educação estética e formação inicial de professores da educação básica: um estudo hermenêutico do projeto político-pedagógico do curso de pedagogia, na modalidade de educação a distância.

Souza, C. P. (1997). Avaliação do rendimento escolar: sedimentação de significados. Em C. P. Sousa (Org.), Avaliação do rendimento escolar (6. ed. pp. 143151): Papirus.

Weisz, T. (2002) O diálogo entre o ensino e a aprendizagem. Ed. Ática,( $2^{\circ}$ ed.).

Zabala, A. (1998) A Prática Educativa. Como ensinar. Tradução de Ernani F. da F. Rosa. Porto Alegre: ARTMED.

Zabala, A. (2015) A prática educativa: como ensinar. 